18 Kaae J, Carstensen L, Wohlfahrt J, Melbye M, Boyd HA. Epilepsy, antiepileptic medication use and risk of cancer. Int J Cancer 2014; 134: 932-8.

19 Singh G, Bell GS, Driever PH, Sander JW. Cancer risk in people with epilepsy using valproate-sodium. Acta Neurol Scand 2012; 125: 234-40.

20 Hallas J, Friis S, Bjerrum L, Stovring H, Narverud SF, Heyerdahl T, et al. Cancer risk in long-term users of valproate: a population-based case-control study. Cancer Epidemiol Biomarkers Prev 2009; 18: 1714-9.

21 Kang $\mathrm{H}$, Gillespie TW, Goodman M, Brodie SA, Brandes M, Ribeiro M, et al. Long-term use of valproic acid in US veterans is associated with a reduced risk of smoking-related cases of head and neck cancer. Cancer 2014; 120 : 1394-400.

22 Boursi B, Lurie I, Mamtani R, Haynes K, Yang YX. Anti-depressant therapy and cancer risk: a nested case-control study. Eur Neuropsychopharmacol 2015; 25: 1147-57.

23 Lee HK, Eom CS, Kwon YM, Ahn JS, Kim S, Park SM. Meta-analysis: selective serotonin reuptake inhibitors and colon cancer. Eur J Gastroenterol Hepatol 2012; 24: 1153-7.

24 Walker AJ, Card T, Bates TE, Muir K. Tricyclic antidepressants and the incidence of certain cancers: a study using the GPRD. Br J Cancer 2011; 104 193-7.

25 Fond G, Macgregor A, Attal J, Larue A, Brittner M, Ducasse D, et al. Antipsychotic drugs: pro-cancer or anti-cancer? A systematic review. Med Hypotheses 2012; 79: 38-42.
26 Lin GM, Chen YJ, Kuo DJ, Jaiteh LE, Wu YC, Lo TS, et al. Cancer incidence in patients with schizophrenia or bipolar disorder: a nationwide population-based study in Taiwan, 1997-2009. Schizophr Bull 2013; 39 $407-16$

27 Hung $\mathrm{Y}-\mathrm{N}$, Yang S-Y, Huang M-C, Lung F-W, Lin S-K, Chen K-Y, et al. Cancer incidence in people with affective disorder: nationwide cohort study in Taiwan, 1997-2010. Br J Psychiatry 2014; 205: 183-8.

28 Health Promotion Administration, Ministry of Health and Welfare. Cancer Registry Annual Report 2010, Taiwan. Health Promotion Administration, Ministry of Health and Welfare, 2010 (http://www.hpa.gov.tw/BHPNet/Web/ Stat/StatisticsShow.aspx?No $=200911300001$ ).

29 Grunze H, Vieta E, Goodwin GM, Bowden C, Licht RW, Moller HJ, et al. The World Federation of Societies of Biological Psychiatry (WFSBP) guidelines for the biological treatment of bipolar disorders: update 2012 on the long-term treatment of bipolar disorder. World J Biol Psychiatry. 2013; 14: 154-219.

30 Bai YM, Chang CJ, Tsai SY, Chen YC, Hsiao MC, Li CT, et al. Taiwan consensus of pharmacological treatment for bipolar disorder. J Chin Med Assoc 2013; 76: 547-56.

31 Rowe MK, Wiest C, Chuang DM. GSK-3 is a viable potential target for therapeutic intervention in bipolar disorder. Neurosci Biobehav Rev 2007; 31 920-31.

\title{
reflection
}

\section{Reflection on Richard Lazarus' Emotion and Adaptation}

\section{Ayat Ali}

Emotion and Adaptation, first published in 1991, is a thorough and scholarly book hypothesising a cognitive theory of emotion Lazarus has been a pioneer in this field for the past 40 years; he argues that emotions have intentionality and that their significance and force are determined by our cognition. This then creates a judgement as to whether or not we can cope with the external event or situation, which forms an emotional reaction.

Lazarus' book helps us understand why emotions are so meaningful to the human race. Drawing together all the related research, it is a centrepiece of work for all those interested in emotion and cognition and applicable to sociologists and psychologists as well as psychiatrists. Lazarus' ideas have attracted my attention as they are, relatively speaking, radical. In today's world the reductionist perspective has dominated explanations for the wonders of the human mind. Mental health conditions have been reduced to chemical imbalances and a pathological structure of the brain, stripping the mind and emotions of all higher meanings.

Lazarus proposes a multidimensional appraisal theory of emotion, where an appraisal is an evaluation of an external event. His theory of emotion can be broken down into a sequence: (1) cognitive appraisal, (2) physiological response, and (3) action. Lazarus endeavoured to answer two questions, the nature of the appraisals which underlie each emotional reaction and the determining antecedent conditions of these appraisals. The answers to these questions would help us understand what emotion is, why we have certain emotions in particular situations and why emotional reactions vary from person to person even in the same or similar situations.

Lazarus' theory merges well with other schools of thought: the somatic theory, the cognitive theory and Skinner's behavioural theory. One of the strengths of the appraisal theory is that it explains the variation of reactions among people subject to the same event. Primary appraisal is the chief factor influencing whether or not an individual can cope in a stressful situation. In contrast, Robert Zajonc states that cognitive processes and affect are independent of each other. Affect precedes cognition and is far more influential; he calls this 'the primacy of affect'. He argued that the affect response could be made sooner than the cognitive response. Zajonc uses the example that infants and animals can make facial expressions highly indicative of emotion with no preceding cognition; this however, cannot be proved.

I cannot help but agree with both Lazarus and Zajonc. I do not believe that their theories are mutually exclusive. I would argue that we could place emotions on a continuum from least cognitive to highly cognitive, basic emotions to complex emotions. Zajonc's theories are most likely to hold true and be the dominant system for lower organisms. Paul Ekman gives a nice analogy of emotions being like primary colours, primary emotions blending into more complex emotions to give the full spectrum of human emotional experience. 